\title{
Screening for primary aldosteronism in an argentinian population: a multicenter prospective study
}

Mariela Leal Reyna', Reynaldo M. Gómez², Susana N. Lupi ${ }^{3}$, Susana H. Belli, Cecilia A. Fenili5 ${ }^{\text {, Marcela S. Martínez }}{ }^{6}$, Gabriela F. Ruibal $^{7}$, María A Rossi², Raúl A Chervin ${ }^{2}$, Dora Cornaló ${ }^{8}$, Liliana N. Contreras ${ }^{9}$, Liliana Costa ${ }^{10}$, María T. Nofall ${ }^{11}$, Sergio A. Damilano ${ }^{5}$, Ester M. Pardes ${ }^{3}$

\begin{abstract}
Objectives: Primary aldosteronism (PA) is characterized by the autonomous overproduction of aldosterone. Its prevalence has increased since the use of the aldosterone (ALD)/plasma renin activity (PRA) ratio (ARR). The objective of this study is to determine ARR and ARC (ALD/plasma renin concentration ratio) cut-off values (COV) and their diagnostic concordance (DC\%) in the screening for PA in an Argentinian population. Design: multicenter prospective study. Subjects and methods: We studied 353 subjects ( 104 controls and 249 hypertensive patients). Serum aldosterone, PRA and ARR were determined. In 220 randomly selected subjects, 160 hypertensive patients and 60 controls, plasma renin concentration (PRC) was simultaneously measured and ARC was determined. Results: According to the $95^{\text {th }}$ percentile of controls, we determined a COV of 36 for ARR and 2.39 for ARC, with ALD $\geq 15 \mathrm{ng} / \mathrm{dL}$. In 31/249 hypertensive patients, ARR was $\geq 36$. PA diagnosis was established in $8 / 31$ patients ( $23 / 31$ patients did not complete confirmatory tests). DC\% between ARR and ARC was calculated. A significant correlation between ARR and ARC $(r=0.742 ; p<0.0001)$ was found only with PRA $>0.3 \mathrm{ng} / \mathrm{mL} / \mathrm{h}$ and PRC $>5 \mathrm{pg} / \mathrm{mL}$. DC\% for ARR and ARC above or below 36 and 2.39 was $79.1 \%$, respectively. Conclusion: This first Argentinian multicenter study determined a COV of 36 for ARR and 2.39 for ARC. Applying an ARR $\geq 36$ in the hypertensive group, we confirmed PA in a higher percentage of patients than the previously reported one in our population. As for ARC, further studies are needed for its clinical application, since DC\% is acceptable only for medium range renin values. Arch Endocrinol Metab. 2015;59(5):441-7
\end{abstract}

Keywords

Aldosterone/plasma renin ratio; primary aldosteronism; essential hypertension; screening; multicenter study
Complejo Médico ChurrucaVisca, Ciudad Autônoma de Buenos Aires, Argentina

2 Hospital de Clínicas José de San Martín, Ciudad Autônoma de Buenos Aires, Argentina ${ }^{3}$ Hospital JM. Ramos Mejía, Ciudad

Autônoma de Buenos Aires, Argentina

${ }^{4}$ Hospital C. Durand, Ciudad Autônoma

de Buenos Aires, Argentina

${ }^{5}$ Laboratorio Bioanalítica, Ciudad

Autônoma de Buenos Aires, Argentina

${ }^{6}$ Hospital C. Milstein, Ciudad Autônoma de Buenos Aires, Argentina

7 Hospital T. Alvarez, Ciudad Autônoma de Buenos Aires, Argentina

${ }^{8}$ Hospital B. Rivadavia, Ciudad

Autônoma de Buenos Aires, Argentina

${ }^{9}$ Instituto de Investigaciones Médicas

Dr. A. Lanari, Ciudad Autônoma

de Buenos Aires, Argentina

${ }^{10}$ Hospital A. Posadas (Provincia de Buenos Aires), Argentina

${ }^{11}$ Clínica Bazterrica, Ciudad Autônoma

de Buenos Aires, Argentina

Correspondence to:

Ester Matilde Pardes

División Endocrinología,

Hospital JM Ramos Mejía

General Urquiza, 609

Ciudad Autónoma de Buenos Aires

(1221), Argentina

epard2003@yahoo.com.ar

Received on May/9/2015

Accepted on May/27/2015

DOI: 10.1590/2359-3997000000075

\section{INTRODUCTION}

$\mathrm{P}$ rimary aldosteronism (PA) described by Jerome Conn in 1955 (1) is a relatively common curable cause of hypertension (HT). Since Hiramatsu and cols. reported that the aldosterone (ALD)/plasma renin activity (PRA) ratio (ARR) showed a higher sensitivity for detecting PA (2), various research groups applied ARR to detect PA in essential hypertensive patients, independently of the potassium levels. Thus, PA prevalence increased to a mean of $7.8 \%$-higher than the $1 \%$ historically reported one in hypokalemic hypertensive patients (3). Furthermore, recent studies have reported the ALD/plasma renin concentration (PRC) ratio as an alternative method of screening $(4,5)$.

We performed a prospective multicenter study in order to determine firstly the cut-off value (COV) for ARR in our population as a screening test for PA in hypertensive patients, regardless of the potassium le- vel (6). Additionally, in a randomly selected subgroup, PRC was simultaneously measured. The aim of this paper is to present our results, to determine the ALD/ $\mathrm{PRC}$ ratio (ARC) and to compare ARR and ARC in order to assess the possible clinical application of ARC by calculating the diagnostic concordance (DC\%) between both ratios.

\section{SUBJECTS AND METHODS}

We performed a prospective multicenter study at the Adrenal Department of the Argentine Society of Endocrinology and Metabolism, comprising 10 hospitals of Buenos Aires. Four hundred and forty subjects of both sexes were recruited in a three-year period. Eighty-seven subjects were excluded due to heart, liver or kidney failure, chronic neuropathy, Cushing's syndrome, glucocorticoid therapy, hyperthyroidism, untreated 
hypothyroidism, hypercalcemia, diabetes mellitus, secondary HT, hormone replacement therapy or missing data. The remaining 353 subjects were divided into two groups: 1) Controls: 104 subjects ( 68 females and 36 males), aged 16 to 77 years old, with blood pressure (BP) measurements $\leq 139 / 85 \mathrm{mmHg}$ and no firstdegree family history of HT. 2) Hypertensive group: 249 patients (193 females and 56 males), aged 17 to 76 years old, with BP measurements $\geq 140 / 90 \mathrm{mmHg}$.

In both groups, the following data was obtained: waist circumference, weight, height, body mass index (BMI) and sitting BP, which was measured on three different days. Serum levels of sodium, potassium, calcium, urea, creatinine, cholesterol, LDL-C, HDL-C, triglycerides, ALD and PRA were determined. Waist circumference less than $102 \mathrm{~cm}$ in males and $88 \mathrm{~cm}$ in females was considered normal. Hypokalemia was defined as serum potassium concentration $<3.5 \mathrm{mEq} / \mathrm{l}$.

PRC was simultaneously measured in a subgroup of 220 randomly selected subjects, 60 controls ( 52 females and 8 males) and 160 hypertensive patients (111 females and 49 males).

Approval was obtained from each hospital ethical committee. Informed consent was obtained from all subjects.

\section{Preanalytical conditions}

Preanalytical conditions were unified and samples were processed in a single laboratory.

Prior to performing baseline sample collection, unrestricted sodium diet was indicated for seven days and potassium was added if needed. Treatments that strongly interfere with the renin-angiotensin system were not allowed; the washout period was 15 days for beta -adrenergic blockers, angiotensin II receptor blockers (ARBs) and diuretics and 6 weeks for spironolactone. $\alpha$-adrenergic blockers, angiotensin converting enzyme inhibitors (ACE-I) and calcium channel blockers (CCBs) were allowed.

Fasting blood samples were drawn from subjects seated for 15 minutes and after at least 2 hours of upright posture between 8.00 and 9.00 AM. Serum samples were used for ALD and PRC and clinical chemistry determination while Na2-EDTA treated plasma samples, obtained by centrifugation at $4^{\circ} \mathrm{C}$ and intended for PRA measurement, were immediately frozen at $-20^{\circ} \mathrm{C}$ until assayed. Each aliquot was thawed once. In all cases, lipemic and/or hemolyzed samples were excluded.

\section{Assay methods and measurements}

ALD was measured by a solid-phase RIA (DPC), with a functional sensitivity of $2 \mathrm{ng} / \mathrm{dL}(20 \mathrm{pg} / \mathrm{mL})$ and intra- and interassay precision of $5.4 \%$ and $15.7 \%$, respectively. Reference range for an ambulatory individual on a normal sodium diet and in an upright position: 4-30 $\mathrm{ng} / \mathrm{dL}(40-300 \mathrm{pg} / \mathrm{mL})$.

PRA was measured by a solid-phase RIA (DIA SORIN) that measures angiotensin I (AT I) generated in vitro, as described by Sealey (7), with an analytical sensitivity of $0.018 \mathrm{ng} \mathrm{AT/tube,} \mathrm{and} \mathrm{an} \mathrm{intra-} \mathrm{and} \mathrm{interas-}$ say precision of $10 \%$.

PRC was measured by a solid-phase IRMA DSL (Diagnostic Systems Laboratories) with an analytical and functional sensitivity of 0.36 and $5.0 \mathrm{pg} / \mathrm{mL}$, respectively, and an intra- and interassay precision of $10 \%$. This method has been standardized against the second reference standard IRP 68/356.

The upper limit of the reference range in ambulatory subjects on a normal sodium diet and in an upright position is $3.3 \mathrm{ng} / \mathrm{mL} / \mathrm{h}$ for ARP and $65 \mathrm{pg} / \mathrm{mL}$ for PRC.

The ARR [ALD (ng/dL)/PRA (ng/mL/hour)] and the ARC $[\operatorname{ALD}(\mathrm{ng} / \mathrm{dL}) / \mathrm{PRC}(\mathrm{pg} / \mathrm{mL})]$ were calculated in hypertensive patients, ARR values were considered suspicious for PA only with ALD $\geq 15 \mathrm{ng} / \mathrm{dL}$, in agreement with other authors $(8,9)$.

Fludrocortisone suppression tests (FST) or saline infusion tests (SIT) were used to confirm PA, according to each participating center. In the FST, ALD was measured at baseline and at $10.00 \mathrm{AM}$ on the fifth day after administration of fludrocortisone $(0.1 \mathrm{mg}$ every 6 hours for four days on an unrestricted sodium diet) and in the SIT, ALD was measured after a 4-hour infusion of two liters of saline solution $(0.9 \%)$. PA was confirmed with ALD levels above $6 \mathrm{ng} / \mathrm{dL}$ in the FST (10) and above $7 \mathrm{ng} / \mathrm{dL}$ in the SIT (11). In all PA patients, adrenal computed tomography was obtained, and in two of them ( 1 adenoma and 1 hyperplasia) adrenal venous catheterization was performed (9).

\section{Diagnostic concordance assessment (DC\%)}

Since PRC measures renin mass concentration and PRA estimates renin enzymatic activity and their results are expressed in different units, both values cannot be directly compared. Therefore, we calculated the DC\% in order to determine if the results obtained by both methods (ARR and ARC) are comparable or provide, 
at least, the same diagnostic information. $\mathrm{DC} \%$ is the percentage obtained from adding the concordant results below (A) and above (B) the COV for ARR and ARC, respectively, divided by the total number of results (concordant and discordant) multiplied by 100 :

$$
\mathrm{DC} \%=\left\{(\mathrm{A}+\mathrm{B}) / \text { total } \mathrm{N}^{\mathrm{o}} \text { of results }\right\} \times 100 .
$$

\section{Statistical analyses}

Normality of variables was analyzed with the ShapiroWilks test. Comparisons were made by the non-parametric Wilcoxon test. Differences between control subjects, essential hypertensive patients and PA hypertensive patients were compared by a non-parametric variance analysis using the Kruskal Wallis test; for posthoc comparisons, the Conover method was used. The relationship between variables was analyzed using the non-parametric Spearman coefficient of correlation $(\rho)$ and its corresponding test to determine whether the correlation is significantly different from zero. Significance was set at $\mathrm{p}<0.05$.

In order to calculate the cut-off values for ARR and ARC, the Collings and Hamilton method and/or the determination of the $95^{\text {th }}$ percentile were used.

\section{RESULTS}

Control subjects had a mean age lower than hypertensive patients $(45.2 \pm 13.8$ vs. $51 \pm 13.6)$; however, the median (47 vs. 53 years) and the range (16-77 vs. 17-76 years) were similar. Both BMI and waist circumference were significantly higher in hypertensive subjects than in controls $(\mathrm{p}<0.0001)$. Hypertensive subjects had a significantly higher serum concentration of creatinine $(\mathrm{p}=0.0001)$, total cholesterol $(\mathrm{p}=0.0165)$, LDL$\mathrm{C}(\mathrm{p}=0.0344)$ and triglycerides $(\mathrm{p}<0.0001)$, while the HDL-C concentration was significantly lower $(\mathrm{p}=$ 0.0078 ). They also had a higher prevalence of metabolic syndrome according to the National Cholesterol Education Program-Adult Treatment Panel III (ATP III) (12). No significant differences were found in blood sodium, glucose or potassium levels (Table 1).

ALD concentrations were similar in both groups, while PRA was significantly lower in hypertensive patients $(p=0.0036)$. Consequently, higher values of ARR were found in hypertensive patients, a finding that reached statistical significance $(\mathrm{p}=0.0002)$.

Since the ARR variable did not show a normal distribution, the cut-off value according to the $95^{\text {th }}$ per- centile was 36.15 . If the $95^{\text {th }}$ percentile is calculated by estimating the empirical distribution function using Collings and Hamilton's method, the COV was 35.79. According to both results, the COV for ARR was set at 36 (Figure 1).

Table 1. Clinical and biochemical characteristics of control subjects and hypertensive patients

\begin{tabular}{|c|c|c|c|}
\hline Variable & $\begin{array}{l}\text { Controls } \\
n=104\end{array}$ & $\begin{array}{l}\text { Hypertensives } \\
n=249\end{array}$ & $\mathbf{p}$ \\
\hline Age (years) & $45.18 \pm 13.78$ & $51.0 \pm 13.6$ & 0.0001 \\
\hline Weight (kg) & $65.68 \pm 16.13$ & $78.0 \pm 17.3$ & $<0.0001$ \\
\hline Height (m) & $1.61 \pm 0.08$ & $1.61 \pm 0.09$ & NS \\
\hline BMI (weight/height²) & $25.25 \pm 5.19$ & $29.9 \pm 6.0$ & $<0.0001$ \\
\hline Waist (cm) & $83.63 \pm 15.32$ & $95.2 \pm 15.7$ & $<0.0001$ \\
\hline $\mathrm{SBP}(\mathrm{mmHg})$ & $114.53 \pm 11.16$ & $152.5 \pm 19.1$ & $<0.0001$ \\
\hline $\mathrm{DBP}(\mathrm{mmHg})$ & $73.05 \pm 8.03$ & $93.8 \pm 11.7$ & $<0.0001$ \\
\hline Creatinine (mg\%) & $0.82 \pm 0.13$ & $0.91 \pm 0.19$ & 0.0001 \\
\hline Potassium (mEq/l) & $4.26 \pm 0.37$ & $4.21 \pm 0.49$ & NS \\
\hline Sodium (mEq/l) & $139.97 \pm 3.23$ & $140.8 \pm 2.9$ & NS \\
\hline Cholesterol (mg\%) & $202.44 \pm 33.86$ & $214.2 \pm 39.6$ & 0.0165 \\
\hline HDL cholesterol (mg\%) & $55.11 \pm 12.94$ & $51.2 \pm 12.15$ & 0.0078 \\
\hline Triglycerides (mg/dL) & $106.33 \pm 41.57$ & $143.8 \pm 73.2$ & $<0.0001$ \\
\hline LDL cholesterol (mg\%) & $126.79 \pm 30.82$ & $135.9 \pm 36.6$ & 0.0344 \\
\hline Blood calcium (mg\%) & $9.34 \pm 0.43$ & $9.33 \pm 0.61$ & NS \\
\hline Blood glucose (mg\%) & $92.81 \pm 11.56$ & $96.7 \pm 8.1$ & NS \\
\hline $\mathrm{ALD}(\mathrm{ng} / \mathrm{dL})$ & $16.23 \pm 8.78$ & $19.03 \pm 14.91$ & NS \\
\hline PRA (ng/mL/h) & $1.84 \pm 1.27$ & $1.54 \pm 1.38$ & 0.0036 \\
\hline ARR & $12.96 \pm 10.23$ & $29.9 \pm 59.7$ & 0.0002 \\
\hline
\end{tabular}

BMI: body mass index; SBP: systolic blood pressure; DBP: diastolic blood pressure; ALD: aldosterone; ARP: plasma renin activity; ARR: aldosterone/plasma renin activity ratio; NS: not significant. To convert aldosterone from ng/dL to pmol//, multiply by 27.7. Values are expressed as mean \pm standard deviation.

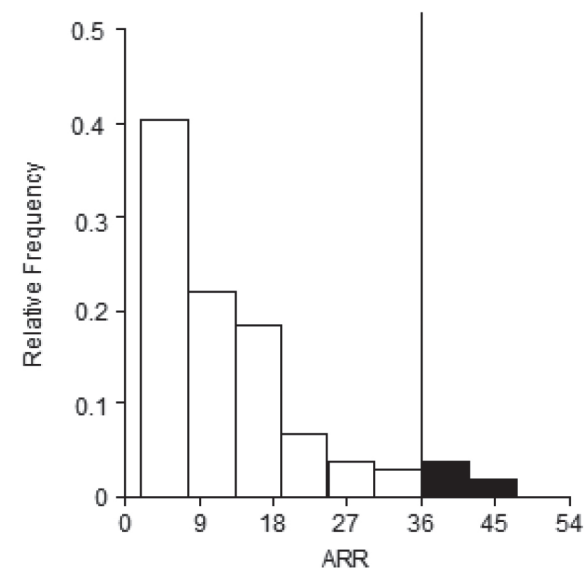

Figure 1. Histogram of aldosterone/plasma renin activity ratio (ARR) values in the 104 controls. The line represents the $95^{\text {th }}$ percentile corresponding to a value of 36 . 
In $12.45 \%$ of hypertensive patients $(31 / 249)$, the ARR was $\geq 36$ with ALD levels $\geq 15 \mathrm{ng} / \mathrm{dL}$. In 8 subjects (4 males and 4 females) confirmation tests were performed, and PA was diagnosed in all cases. The range of post-suppression ALD levels was 12-25 ng/dL. Seven patients had aldosterone-producing adenomas (APA) and the remaining one had idiopathic hyperplasia. Compared to all other hypertensive subjects, PA patients showed higher ALD and ARR values $(\mathrm{p}=0.001)$ and significantly lower potassium concentrations $(\mathrm{p}=$ $0.001)$. In the PA patients, $7 / 8$ had kalemia $<3.5 \mathrm{mE}$ $\mathrm{q} / \mathrm{l}$ and $\mathrm{l} / 8,3.7 \mathrm{mEq} / \mathrm{l}$ (Table 2 ).

Table 2. Serum concentration of ALD, PRA, ARR and blood potassium in hypertensive patients with primary aldosteronism (PA) and without PA (non-PA)

\begin{tabular}{lccc}
\hline Variable & $\begin{array}{c}\text { non- } \mathbf{P A} \\
\mathbf{n = 2 4 1}\end{array}$ & $\begin{array}{c}\text { PA } \\
\mathbf{n = 8}\end{array}$ & $\mathbf{p}$ \\
\hline ALD ng/dL & $17.6 \pm 10.07$ & $61.2 \pm 47.9$ & 0.001 \\
PRA ng/mL/h & $1.58 \pm 1.38$ & $0.34 \pm 0.33$ & 0.001 \\
ARR & $22.3 \pm 26.44$ & $258 \pm 202$ & 0.001 \\
Blood potassium (mEq/l) & $4.25 \pm 0.41$ & $2.94 \pm 0.72$ & 0.001 \\
\hline
\end{tabular}

ALD: serum aldosterone; PRA: plasma renin activity; ARR: aldosterone/plasma renin activity ratio. To convert aldosterone from $\mathrm{ng} / \mathrm{dL}$ to $\mathrm{pmol} / \mathrm{l}$, multiply by 27.7 . Results are expressed as mean \pm standard deviation.

PA was confirmed in $3.2 \%$ of our hypertensive patients but, since the confirmatory diagnostic evaluation could not be completed in the remaining 23 patients with $A R R \geq 36$, the actual prevalence rate cannot be accurately established.

No correlation was found between the severity of HT and ARR either in the hypertensive group as a whole or in the PA patients. Likewise, no correlation was found between ARR levels and systolic and diastolic blood pressure (SBP and DBP, respectively) using the Spearman coefficient of correlation.

In the hypertensive group - with or without PA - no significant differences were found in BMI, waist circumference, $\mathrm{SBP}$ and $\mathrm{DBP}$ readings, plasma concentrations of HDL-C, LDL-C, triglycerides, cholesterol and glucose.

\section{PRC subgroup}

In this subgroup, neither PRA nor PRC showed significant differences between controls and HT. ALD levels were significantly higher in hypertensive patients than in controls (Table 3 ).

The analysis of the relationship between PRC and PRA, both in the whole group and in the subgroup of hypertensive patients (Spearman $\rho$ ), showed a significant correlation between PRC and PRA only in the 143 patients with PRC values between 5 and $20 \mathrm{pg} / \mathrm{mL}(\mathrm{p}<0.001)$.

Table 3. Plasma concentration of ALD, PRA, PRC, ARR and ARC in control subjects and in hypertensive patients

\begin{tabular}{lccc}
\hline Variable & $\begin{array}{c}\text { Controls } \\
\mathbf{n}=\mathbf{6 0}\end{array}$ & $\begin{array}{c}\text { Hypertensives } \\
\mathbf{n}=\mathbf{1 6 0}\end{array}$ & $\mathbf{p}$ \\
\hline ALD $(\mathrm{ng} / \mathrm{dL})$ & $14.36 \pm 8.70$ & $19.69 \pm 17.27$ & 0.007 \\
PRA $(\mathrm{ng} / \mathrm{mL} / \mathrm{h})$ & $1.53 \pm 1.12$ & $1.50 \pm 1.33$ & $\mathrm{NS}$ \\
$\mathrm{PRC}(\mathrm{pg} / \mathrm{mL})$ & $13.92 \pm 11.13$ & $13.25 \pm 13.64$ & $\mathrm{NS}$ \\
ARR & $14.43 \pm 12.50$ & $29.45 \pm 57.39$ & 0.018 \\
ARC & $1.39 \pm 1.31$ & $2.28 \pm 3.10$ & 0.001 \\
\hline
\end{tabular}

ALD: aldosterone; PRA: plasma renin activity; PRC: plasma renin concentration; ARR: aldosterone/plasma renin activity ratio; ARC: aldosterone/plasma renin ratio; NS: not significant. To convert aldosterone from $\mathrm{ng} / \mathrm{dL}$ to $\mathrm{pmol} / \mathrm{l}$, multiply by 27.7 . Values are expressed as mean \pm standard deviation.

As the ARC variable did not show a normal distribution, the cut-off value according to the $95^{\text {th }}$ percentile was 2.41 when it was directly calculated. If it is calculated by estimating the empirical distribution function using the method proposed above, the COV is 2.39 .

In the 220 subjects evaluated, we found a significant correlation between ARR and ARC $(\mathrm{r}=0.742 ; \mathrm{p}<0.0001)$ results, which was similar in the control group and in the hypertensive patients - which included 5/8 PA patients.

Even though ARR and ARC are not comparable in absolute values, the percentage of consistent results above or below 36 for ARR and 2.39 for ARC was 79.1\%: $[(153+21) / 220] \times 100$. Therefore, the DC\% between the results of ratios is $79.1 \%$ (Figure 2).

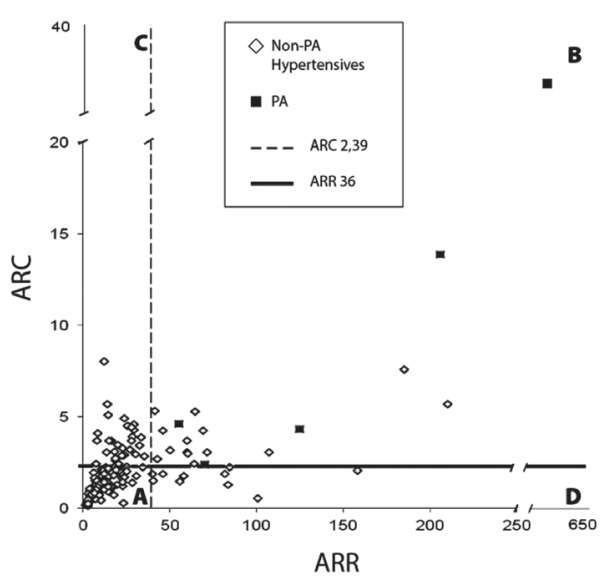

Figure 2. Diagnostic concordance between aldosterone/renin ratio (ARC) and aldosterone/plasma renin activity ratio (ARR). Results in primary aldosteronism (PA) hypertensive patients and non-PA hypertensive patients are shown. Areas A and B represent concordant results; areas $C$ and $D$ represent non-concordant results. (A) Results below the cut-off values (COV) by both methods. (B) Results above the COV by both methods. (C) Results below the COV for ARR and above the COV for ARC. (D) Results above the COV for ARR and below the COV for ARC. 
If results are evaluated according to PRA and PRC ranges studied, discordance between ARR and ARC is greater in samples with PRA below $0.3 \mathrm{ng} / \mathrm{mL} / \mathrm{h}$ and PRC below $5.0 \mathrm{pg} / \mathrm{mL}$ than in samples with medium to high levels (Table 4).

Table 4. DC\% observed between ARR and ARC results in samples selected according to the levels of PRC or PRA

\begin{tabular}{lc}
\hline $\begin{array}{l}\text { Selection criterion: ARR and ARC results } \\
\text { obtained from samples with: }\end{array}$ & DC\% \\
\hline$P R C<5 \mathrm{pg} / \mathrm{mL}$ & 68 \\
$\mathrm{PRC}>5 \mathrm{pg} / \mathrm{mL}$ & 88 \\
$\mathrm{PRA}<0.3 \mathrm{ng} / \mathrm{mL} / \mathrm{h}$ & 59 \\
$\mathrm{PRA} 0.3-3.3 \mathrm{ng} / \mathrm{mL} / \mathrm{h}$ & 86 \\
$\mathrm{PRA}>3.3 \mathrm{ng} / \mathrm{mL} / \mathrm{h}$ & 87 \\
\hline
\end{tabular}

DC\%: diagnostic concordance; ARR: aldosterone/plasma renin activity ratio; ARC: aldosterone/ plasma renin ratio; PRC: plasma renin concentration; PRA: plasma renin activity.

\section{DISCUSSION}

In our control group, the cut-off value for ARR was set at 36. ARR may be significantly modified by a decrease in PRA levels, which does not necessarily imply the presence of autonomous ALD secretion; therefore many authors only take into account the ARR value when serum ALD levels exceed a specific concentration $(8,9,13)$. Thus, we required an ALD concentration $\geq 15 \mathrm{ng} / \mathrm{dL}$ as a further requisite for applying ARR in our hypertensive patients. According to these criteria, the estimated PA prevalence would be $3.2 \%$, but this percentage is most probably not representative of the true PA prevalence, since confirmatory tests could be performed only in $8 / 31$ patients with $A R R \geq 36$. Unfortunately, 23/31 patients with ARR $\geq 36$ did not return to perform these tests - despite being repeatedly called for this purpose. Nevertheless, the percentage we found in our study is still higher than the previously reported one $(0.82 \%)$ in a population of Buenos Aires, where the screening for PA was based on the criteria of hypertension and hypokalemia (14).

ARR is widely used as a screening test for PA in hypertensive patients. However, its results may be modified by factors such as patient selection, sampling conditions, sample storage and processing, absence of standardized laboratory methods and variations in PRA and ALD due to geographical location and ethnicity (1318) - leading to difficulties in establishing a universal cut-off value. Thus, published reports show a wide range of ARR cut-off levels - between 20 and 100, although most authors report values between 25 and 40 (3).
PA prevalence ranges from 0.7 to $27 \%$ with a mean of $7.8 \%$ (3). In agreement with our data, a multicenter study in 1236 unselected hypertensive patients found a prevalence of PA of $3.3 \%$ (19).

Although PA prevalence has been reported to increase according to HT severity $(20,21)$, we have not observed a correlation between ARR and higher blood pressure in hypertensive subjects as a whole or in PA patients, in accordance with Bussolengo's findings (22).

In our hypertensive patients, we ensured an adequate sodium and potassium supply before sampling and appropriate washout periods from diuretics, beta -adrenergic blockers, ARBs and spironolactone. Treatment with ACE-I, $\alpha$-adrenergic blockers and CCBs was allowed, as these drugs have little or no impact on the renin-angiotensin system (23). There is no agreement on this point among different authors. According to clinical practice guidelines, only drugs with minimal or no effects on plasma ALD levels, such as non-dihydropyridine CCBs, hydralazine and $\alpha$-adrenergic blockers (prazosin, doxazosin, terazosin), can be used for the control of blood pressure during screening tests (24). Nevertheless, according to Young, the study is valid even under treatment with ACE-I and ARBs, since low renin levels in these conditions would increase the degree of suspicion of PA (9).

In our study, we observed an increased prevalence of metabolic syndrome in hypertensive patients as compared with controls, but in agreement with other reports (25), we found no differences between PA and essential hypertensive patients. Neither Fallo and cols. (26) nor Catena and cols. (27) found differences in the lipid profile between PA patients and those with essential hypertension, despite the higher prevalence of metabolic syndrome and insulin resistance in PA patients versus controls. Furthermore, ALD may exert a direct effect on insulin receptor function (28) and decrease insulin sensitivity in human adipocytes (29).

There was no correlation between age and ALD concentration or PRA either in controls or in hypertensive patients (data not shown). This is consistent with findings reported by other authors evaluating normotensive subjects (30) and hypertensive patients (31), but it differs from other author's reports (32), where both ALD and PRA were found to decrease with age.

In our study, eight PA cases were confirmed in 249 hypertensive patients. Unlike other studies, the 7 patients with APA had hypokalemia. This situation is usually associated with disturbances of internal milieu, 
as reported in the PAPY study, where a higher prevalence of hypokalemia was shown in subjects with adenoma (48\%) than in those with hyperplasia (17\%) (21).

Regarding PRC determination, this methodology has many advantages over PRA $(33,34)$ : less demanding preanalytical conditions (serum vs. plasma), shorter incubation times and direct measurement of the renin molecule, which makes it more applicable to the clinical diagnostic laboratory and less operator-dependent, narrowing interlaboratory coefficients of variation. This method is calibrated against the WHO standard IRP 68/356 (NIBSC), which ensures traceability. Additionally, in recent years automated methodology for PRC measurement has been developed. The disadvantages include greater prorenin cryoactivation effects and less sensitivity when measuring low renin concentrations (35). Since PRC and ALD/renin ratio have been proposed for PA screening $(4,5)$, we determined PRC in a subgroup of randomly selected controls and hypertensive patients.

PRC and PRA results have a significant correlation in subjects with PRC values ranging between 5 and 20 $\mathrm{pg} / \mathrm{mL}(\mathrm{p}<0.001)$. A significant correlation was also found between ARR and ARC both in controls and hypertensive patients $(\mathrm{p}<0.0001)$.

PRA and PRC are not comparable in absolute values because PRC measures renin concentration, while PRA measures enzyme activity and their results are expressed in different units. When comparing ARR vs. ARC, the diagnostic concordance of values above or below 36 or 2.39 for ARR and ARC respectively, was $79.1 \%$. Our comparative analysis of ARR and ARC data shows that $\mathrm{DC} \%$ is acceptable only for PRA values $\geq 0.3 \mathrm{ng} / \mathrm{mL} / \mathrm{h}$ $(86 \%)$ and $\mathrm{PRC} \geq 5.0 \mathrm{pg} / \mathrm{mL}(88 \%)$.

In conclusion, this first multicenter prospective study performed in Argentina establishes a cut-off value for ARR in our population. In hypertensive patients, we consider $A R R \geq 36$ along with $A L D \geq 15 \mathrm{ng} / \mathrm{dL}$, as suspicious for PA. Applying an ARR $\geq 36$ in the hypertensive group, and even taking into consideration that confirmatory tests could not be performed in all hypertensives with $A R R \geq 36$, we found that PA was confirmed in a higher percentage of patients than the previously reported one in our population. As for ARC, further studies are needed for its clinical application, since the diagnostic concordance between ARR and ARC is acceptable only for medium range renin values.

Fundings: this research did not receive any specific grant from any funding agency in the public, commercial or not-for-profit sector.

Disclosure: no potential conflict of interest relevant to this article was reported.

\section{REFERENCES}

1. Conn JW. Presidential address. I. Painting background. II. Primary aldosteronism, a new clinical syndrome. J Lab Clin Med. 1955;45(1):3-17.

2. Hiramatsu K, Yamada T, YukimuraY, Komiya I, Ichikawa K, Ishihara $M$, et al. A screening test to identify aldosterone-producing adenoma by measuring plasma renin activity. Results in hypertensive patients. Arch Intern Med. 1981;141(12):1589-93.

3. Jansen PM, Boomsma F, van den Meiracker AH; Dutch ARRAT Investigators. Aldosterone-to-renin ratio as a screening test for primary aldosteronism - the Dutch ARRAT Study. Neth J Med. 2008;66(5):220-8.

4. Ferrari P, Shaw SG, Nicod J, Saner E, Nussberger J. Active renin versus plasma renin activity to define aldosterone-to-renin ratio for primary aldosteronism. J Hypertens. 2004;22(2):377-81.

5. Corbin F, Douville $P$, Lebel M. Active renin mass concentration to determine aldosterone-to-renin ratio in screening for primary aldosteronism. Int J Nephrol Renovasc Dis. 2011;4:115-20.

6. Pardes E, Belli S, Cornaló D, Contreras L, Costa L, Chervin R, et al. Determinación del valor de corte de la relación aldosterona/ actividad de renina plasmática para la detección de hiperaldosteronismo primario en hipertensión arterial esencial: estudio multicéntrico Rev Argent Endocrinol Metab. 2010;47(2):27-39.

7. Sealey JE. Plasma renin activity and plasma prorenin assays. Clin Chem. 1991;37(10 Pt 2):1811-9.

8. Mulatero P, Dluhy RG, Giacchetti G, Boscaro M, Veglio F, Stewart PM. Diagnosis of primary aldosteronism: from screening to subtype differentiation. Trends Endocrinol Metab. 2005;16(3):114-9.

9. Young WF. Primary aldosteronism: renaissance of a syndrome. Clin Endocrinol (Oxf). 2007;66(5):607-18.

10. Stowasser M, Gordon RD, Gunasekera TG, Cowley DC, Ward G, Archibald $\mathrm{C}$, et al. High rate of detection of primary aldosteronism, including surgically treatable forms, after 'non-selective' screening of hypertensive patients. J Hypertens. 2003;21(11):2149-57.

11. Giacchetti G, Ronconi V, Lucarelli G, Boscaro M, Mantero F. Analysis of screening and confirmatory tests in the diagnosis of primary aldosteronism: need for a standardized protocol. J Hypertens. 2006;24(4):737-45.

12. Executive Summary of the Third Report of the National Cholesterol Education Program (NCEP). Expert Panel on Detection, Evaluation, and Treatment of High Blood Cholesterol in Adults (Adult Treatment Panel III). JAMA. 2001;285:2486-97.

13. Mulatero P, Stowasser M, Loh KC, Fardella CE, Gordon RD, Mosso $\mathrm{L}$, et al. Increased diagnosis of primary aldosteronism, including surgically correctable forms, in centers from five continents. J Clin Endocrinol Metab. 2004;89(3):1045-50.

14. Marín M, Gómez RM, González Boix J, Fábregues G, Baglivo HP, Larrart M el al. Mayor incidencia de hiperaldosteronismo idiopático en pacientes con aldosteronismo primario. Rev Argent Cardiol. 1997;65(Supl. 3):71-6.

15. Stowasser M, Ahmed AH, Pimenta E, Taylor PJ, Gordon RD. Factors affecting the aldosterone/renin ratio. Horm Metab Res. 2012;44(3):170-6.

16. Fardella CE, Mosso L, Gómez-Sánchez C, Cortés P, Soto J, Gómez $L$, et al. Primary hyperaldosteronism in essential hypertensives: prevalence, biochemical profile, and molecular biology. J Clin Endocrinol Metab. 2000;85(5):1863-7.

17. Rayner BL, Myers JE, Opie LH, Trinder YA, Davidson JS. Screening for primary aldosteronism - normal ranges for aldosterone and renin in three South African population groups. S Afr Med J. 2001;91(7):594-9.

18. Nishizaka MK, Pratt-Ubunama M, Zaman MA, Cofield S, Calhoun DA. Validity of plasma aldosterone-to-renin activity ratio in Afri- 
can American and white subjects with resistant hypertension. Am J Hypertens. 2005;18(6):805-12.

19. Naruse M, Tanaka T, Otani S, Ogo A, Tanabe M, Ishikawiza N, et al.; PHAS-J Study Group. Prevalence of primary hyperaldosteronism in patients with hypertension in Japan (PHAS-J): Prospective Multicenter Study of National Hospital Organization Network. 91 $1^{\text {th }}$ Annual Meeting of The Endocrine Society. ENDO'09. 2009 June 10-13; Washington, DC. p. 2-671.

20. Mosso L, Carvajal C, González A, Barraza A, Avila F, Montero J, et al Primary aldosteronism and hypertensive disease. Hypertension. 2003;42(2):161-5.

21. Rossi GP, Bernini G, Caliumi C, Desideri G, Fabris B, Ferri C, et al.; PAPY Study Investigators. A prospective study of the prevalence of primary aldosteronism in 1,125 hypertensive patients. J Am Coll Cardiol. 2006;48(11):2293-300.

22. Olivieri 01, Ciacciarelli A, Signorelli D, Pizzolo F, Guarini $P$, Pavan $\mathrm{C}$, et al. Aldosterone to Renin ratio in a primary care setting: the Bussolengo study. J Clin Endocrinol Metab. 2004;89(9):4221-6.

23. Mulatero P, Rabbia F, Milan A, Paglieri C, Morello F, Chiandussi L, et al. Drug effects on aldosterone/plasma renin activity ratio in primary aldosteronism. Hypertension. 2002;40(6):897-902.

24. Funder JW1, Carey RM, Fardella C, Gomez-Sanchez CE, Mantero F, Stowasser M, et al.; Endocrine Society. Case detection, diagnosis, and treatment of patients with primary aldosteronism: an endocrine society clinical practice guideline. J Clin Endocrinol Metab. 2008;93(9):3266-81.

25. Matrozova J, Steichen O, Amar L, Zacharieva S, Jeunemaitre X, Plouin PF. Fasting plasma glucose and serum lipids in patients with primary aldosteronism: a controlled cross-sectional study. Hypertension. 2009;53(4):605-10.
26. Fallo F, Federspil G, Veglio F, Mulatero P. The metabolic syndrome in primary aldosteronism. Curr Hypertens Rep. 2007;9(2):106-11.

27. Catena C1, Lapenna R, Baroselli S, Nadalini E, Colussi G, Novello $M$, et al. Insulin sensitivity in patients with primary aldosteronism: a follow-up study. J Clin Endocrinol Metab. 2006;91(9):3457-63.

28. Corry DB, Tuck ML. The effect of aldosterone on glucose metabolism. Curr Hypertens Rep. 2003;5(2):106-9.

29. Kraus $D$, Jäger J, Meier B, Fasshauer M, Klein J. Aldosterone inhibits uncoupling protein-1, induces insulin resistance, and stimulates proinflammatory adipokines in adipocytes. Horm Metab Res. 2005;37(7):455-9.

30. Tuck ML, Williams GH, Cain JP, Sullivan JM, Dluhy RG. Relation of age, diastolic blood pressure and known duration of hypertension to presence of low renin hypertension. Am J Cardiol. 1973;32:637-42.

31. Abd-Allah NM, Hassan FH, Esmat AY, Hammad SA. Age dependence of the levels of plasma norepinephrine, aldosterone, renin activity and urinary vanillylmandelic acid in normal and essential hypertensives. Biol Res. 2004;37(1):95-106.

32. Belmin J, Lévy BI, Michel JB. C Changes in the renin-angiotensinaldosterone axis in later life. Drugs Aging. 1994;5(5):391-400.

33. de Bruin RA, Bouhuizen A, Diederich S, Perschel FH, Boomsma F, Deinum J. Validation of a new automated renin assay. Clin Chem. 2004;50(11):2111-6.

34. Simon D, Hartmann DJ, Badouaille G, Caillot G, Guyenne TT, Corvol $P$, et al. Two-site direct immunoassay specific for active renin. Clin Chem. 1992;38(10):1959-62.

35. Campbell DJ, Nussberger J, Stowasser M, Danser AH, Morganti A, Frandsen $E$, et al. Activity assays and immunoassays for plasma Renin and prorenin: information provided and precautions necessary for accurate measurement. Clin Chem. 2009;55(5):867-77. 